\title{
CALVING ICE WALLS
}

\author{
by
}

T. Hughes

(Institute for Quaternary Studies and Department of Geological Sciences, University of Maine, Orono, ME 04469, U.S.A.)

\section{ABSTRACT}

Calving ice walls are an important ablation mechanism for deglaciation of calving bays occupied by temperate tide-water glaciers and polar marine ice sheets. Dangers inherent in calving bays have precluded detailed field studies of these calving ice walls. However, calving ice walls also exist in sub-polar glaciers terminating on dry land, and an opportunity for detailed field work was afforded by the 12 August 1970 volcanic eruption on Deception Island $\left(63.0^{\circ} \mathrm{S}, 60.6^{\circ} \mathrm{W}\right)$, where thawing of a surface blanket of ice-cemented ash produced solifluction ramps that made parts of the ice wall accessible. Measurements made in a melt-water trough incised into the ice wall, and in four tunnels cut into the ice wall, revealed numerous shear bands that rose almost vertically and curved forward. Shear offset increased upward and was greatest in shear bands that intersected the tips of ring-fault crevasses on the up-slope side of the ice wall. Near the base of the ice wall, other shear bands, possibly related to the slip-line field, intersected the ice wall at about $45^{\circ}$. Ice slabs separated by ring faults calved straight down as a result of shear rupture along these two sets of shear bands. Calving dynamics were analyzed and generalized for ice walls grounded in water.

\section{INTRODUCTION}

An ice wall is the ice cliff of a glacier terminus that is grounded on land or in water too shallow to float the ice. Calving of slabs from ice walls is a major ablation mechanism in calving bays, as is seen in Figure 1 for Rinks Glacier $\left(71.7^{\circ} \mathrm{N}, 51.5^{\circ} \mathrm{W}\right)$ in Greenland. Slab calving is also observed along the ice walls of temperate tide-water glaciers, polar valley glaciers, and marine margins of the Greenland and Antarctic ice sheets. Iken (1977) developed a numerical model of calving from an ice wall undercut by inter-tidal wave action on a beach. She assumed

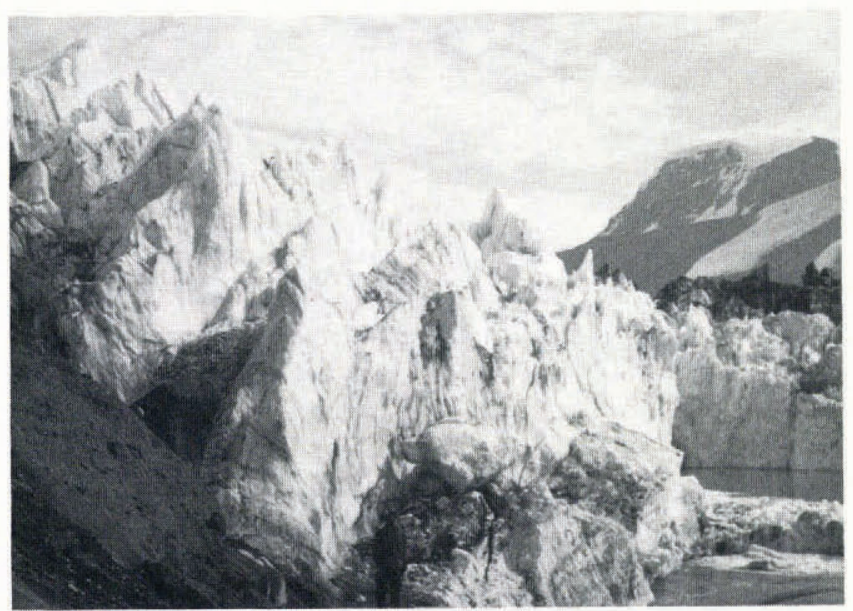

Fig. 1. Slabs calving into a calving bay from the ice wall of Rinks Glacier $\left(71.7^{\circ} \mathrm{N}, 51.5^{\circ} \mathrm{W}\right)$, Greenland. homogeneous creep in the ice. However, direct observation of a calving ice wall on Deception Island $\left(63.0^{\circ} \mathrm{S}, 60.6^{\circ} \mathrm{W}\right)$ revealed that highly inhomogeneous creep deformation leads to slab calving of the characteristic type shown in Figure 1. This paper describes the observed calving mechanism.

Deceptlon Island is a collapsed volcanic caldera of the Antarctic Peninsula. It experienced volcanic eruptions in 1967, 1969, and 1970. The 12 August 1970 eruption blew away the snout of a glacier that extended nearly to sealevel from the glacierized caldera rim, leaving a crater whose up-slope side was an ice wall. The crater was initially about $500 \mathrm{~m}$ in diameter and the ice wall was initially about $100 \mathrm{~m}$ high. Figure 2 locates Deception Island and the crater. Glaciological field studies on the glacier and its calving ice wall were conducted during the 1970-71, 1972-73, 1973-74, and 1982-83 Antarctic summers (Hughes, $1971,1973,1974)$. Preliminary analyses of mass-balance and ice-dynamics studies on the glacier surface were reported by Brecher and others (1974) and Hughes and others (1974).

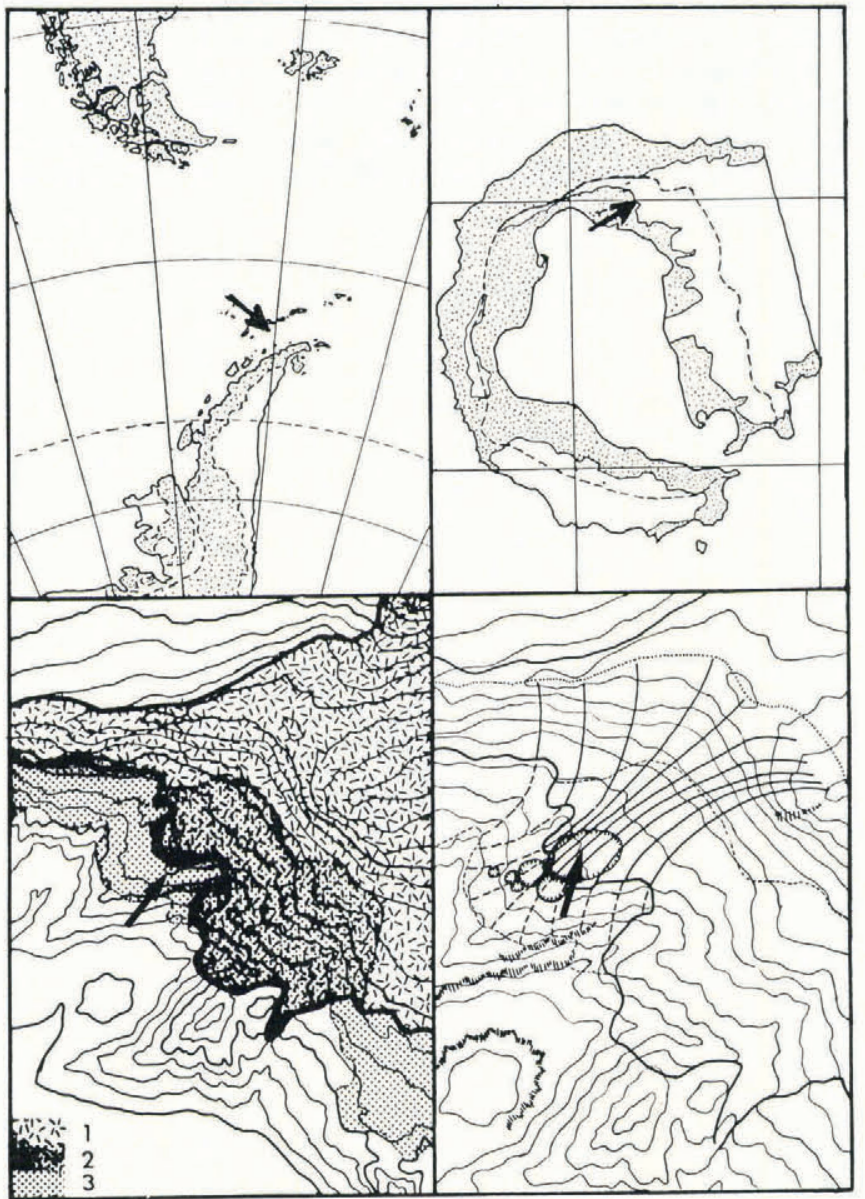

Fig. 2. Location map for the 12 August 1970 subglacial volcanic eruption on Deception Island $\left(63.0^{\circ} \mathrm{S}, 60.6^{\circ} \mathrm{W}\right)$, Antarctica. Upper right: unglaciated areas are dotted. Lower left: accumulation zone (1), ablation zone (2), ash blanket (3), before the eruption. 


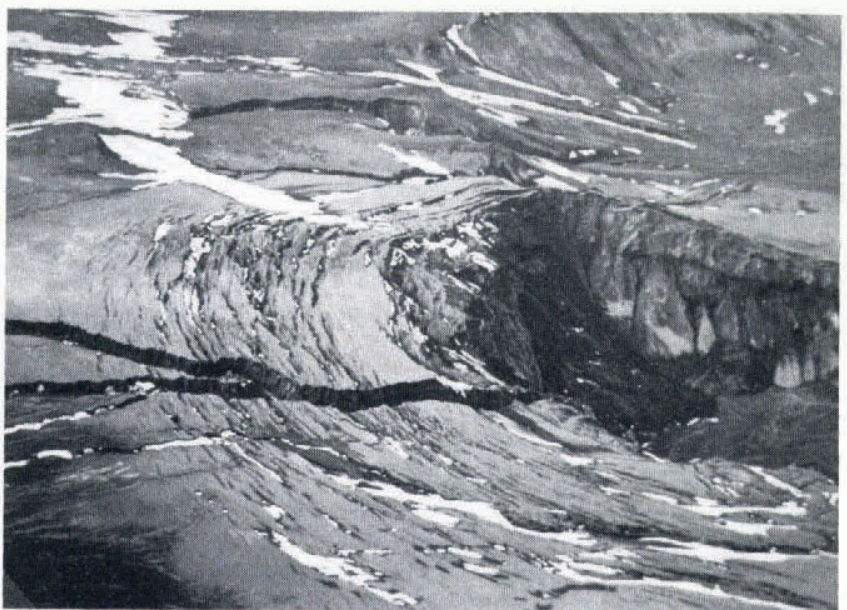

Fig. 3. Ring faults up-slope from the calving ice wall of the crater produced by the 12 August 1970 eruption on Deception Island.

\section{INHOMOGENEOUS DEFORMATION}

Figure 3 shows the pattern of inhomogeneous deformation in the glacier up-slope from the crater 3 months after the eruption. The surface manifestation of inhomogeneous deformation is the array of concentric ring faults in ice-cemented ash that blanketed the glacier as wet ash during the eruption and subsequently became permafrost. Near the crater, crevasses open along the ring faults and slabs of ice between these crevasses calve in succession into the crater. Farther up-slope, slumping toward the crater occurs along ring faults. Figure 4 shows plastic slip lines in plan and longitudinal cross-section that are compatible with

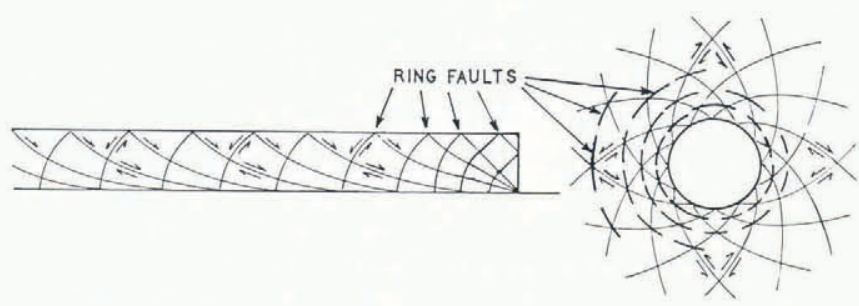

LONGITUDINAL CROSS-SECTION

PLAN VIEW

Fig. 4. Idealized slip lines for down-slope plastic creep toward the crater in Figure 3. Left: longitudinal cross-section showing cycloidal, polar, and rectilinear orthogonal slip lines. Right: surface plan view showing logarithmic spiral orthogonal slip lines. (Adapted from Nadai, 1950.)

these observations. In plan view, surface slip lines are orthogonal logarithmic spirals of the type produced by plastic flow toward a circular cavity (Nadai, 1950, p. 359). In longitudinal cross-section, slip lines are orthogonal half-cycloids well up-slope from the crater, where slumping suggests active flow (Nye, 1951, p. 566), but closer to the crater they become orthogonal radii and arcs originating from the base of the ice wall and orthogonal straight lines intersecting the ice wall at $45^{\circ}$ angles (Nadai, 1951, p. 555). How plan and profile slip lines interact in three dimensions is unknown.

Figure 5 shows ice slabs about to calve at the top of the ice wall and also shows that ring faults extended into glacial ice beneath the ice-cemented ash layer. Figure 6 relates advance of the ice wall to surface lowering in the 29 months following the eruption, as determined by photogrammetric mapping (Brecher and others, 1974). Surface-strain networks shown in Figure 6 revealed that surface lowering was closely related to slumping along ring faults (Hughes and others, 1974).

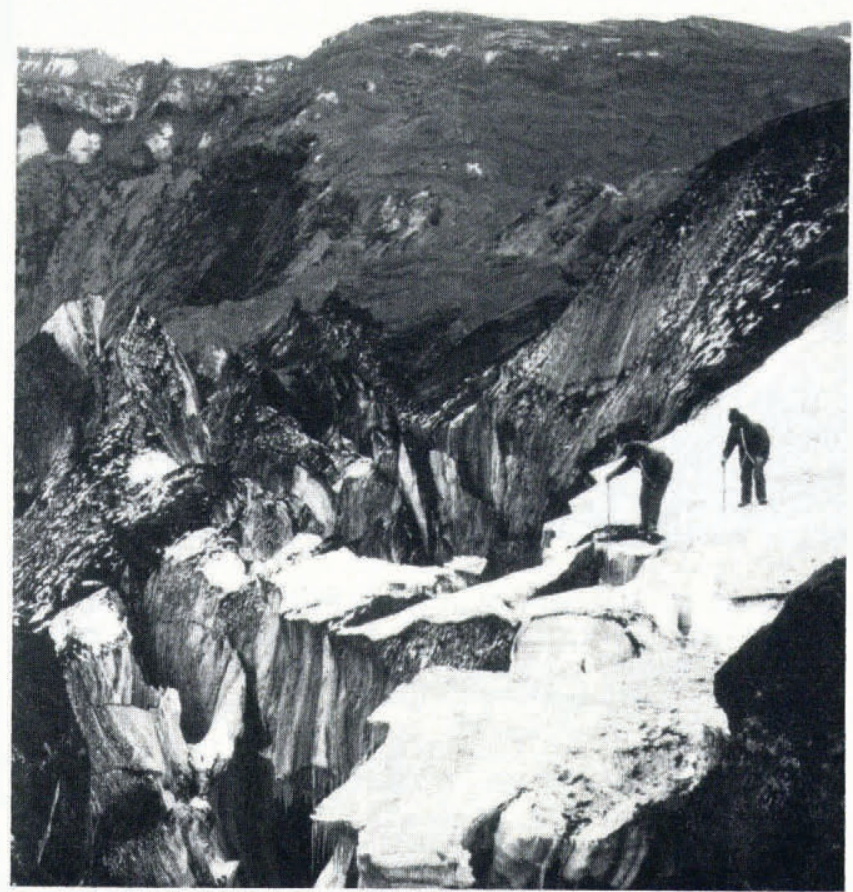

Fig. 5. Slabs about to calve from the up-slope ice wall of the crater in Figure 3.

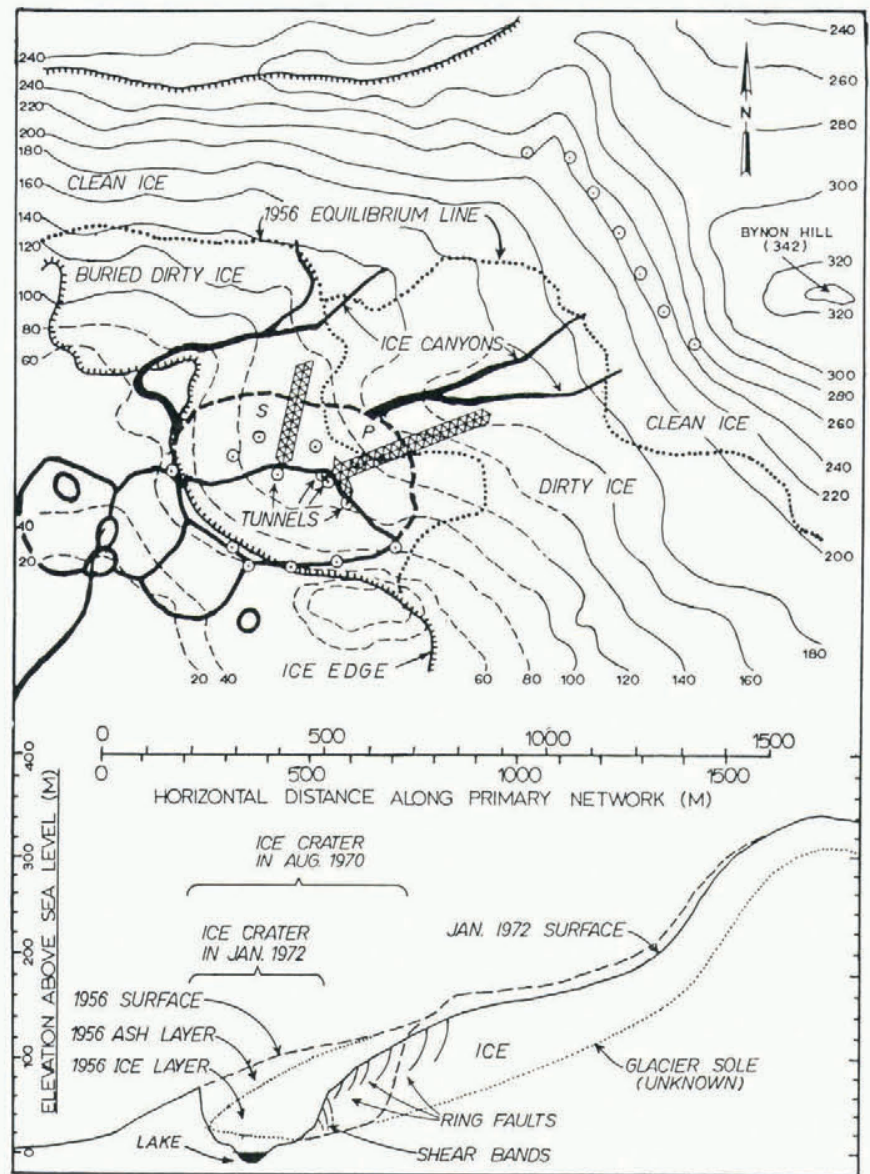

Fig. 6. Location map for field studies of the permafrostblanketed ice moving down-slope into the crater in Figure 3. Shown are surface strain networks trending northnorth-east and east-north-east, mass-balance and ice-velocity stakes used as ground control for photogrammetric and gravity mapping (circled dots), and locations of tunnels cut into the ice wall. The dashed and solid heavy lines show crater closure due to creep from August 1970 to January 1972. 

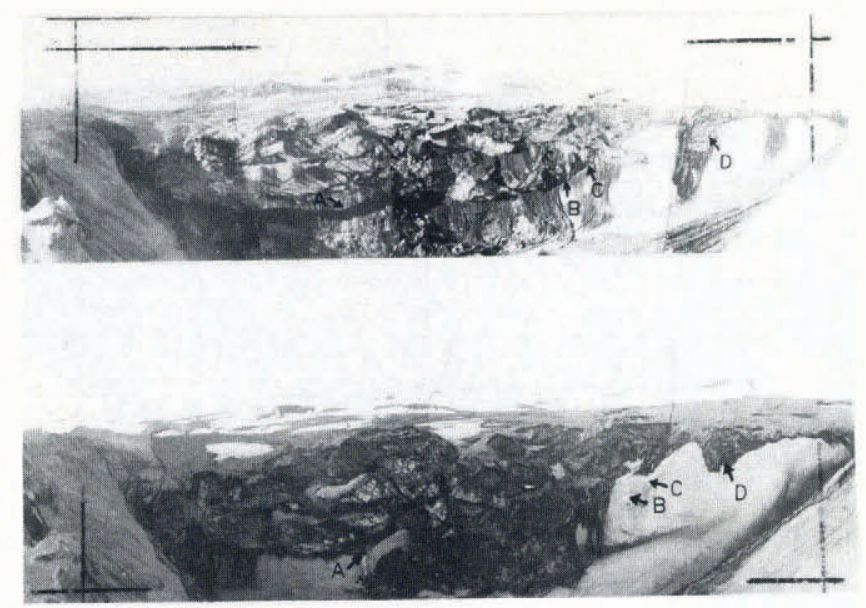

Fig. 7. A photomosaic of the calving ice wall showing tunnel sites A, B, C, and D. Top: the 1972-73 austral summer. Bottom: the 1973-74 austral summer. (Photomosiac by H.H. Brecher.)

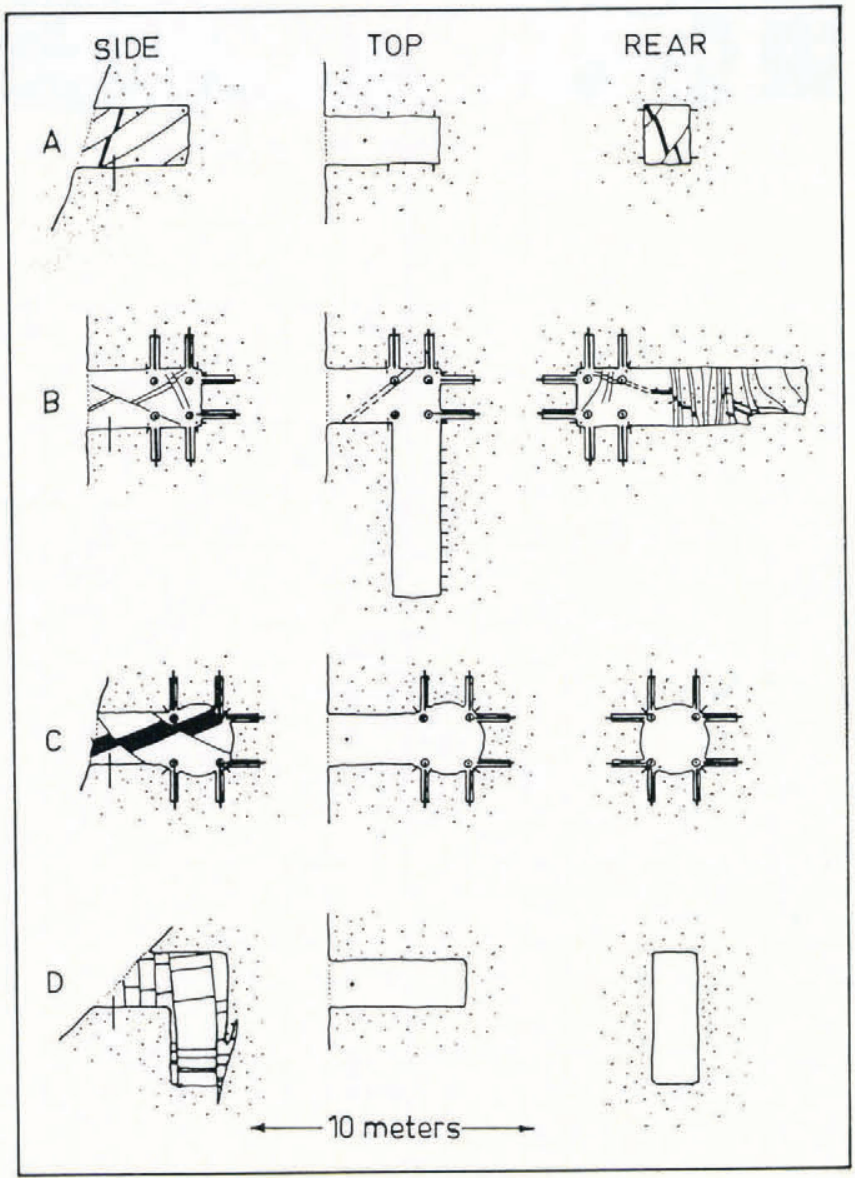

Fig. 8. Ice tunnels A, B, C, and D in Figure 7. Shown are shear bands and ash layers exposed in the tunnels, and strain networks on the tunnel walls and set at the ends of holes drilled into the walls.

A calving ice wall can be quite dangerous, especially if it is grounded in water, because calving occurs without warning and field workers at the ice wall have little mobility. On Deception Island, however, summer thawing in the upper part of the permafrost layer led to solifluction of wet ash into the crater, producing several ash ramps of various heights. By climbing these ramps, field workers could study many parts of the ice wall in relative safety. Four tunnels, shown in Figures 6, 7, and 8, were dug into the ice wall at various heights for the purpose of linking inhomogeneous deformation in the ice wall with inhomogeneous up-slope deformation revealed by the surface ring faults and the surface-strain networks.
Tunnel A was dug near the base of the north ice wall. As seen in Figure 8, inhomogeneous deformation was concentrated in shear bands in which total shear displacement was recorded as offsets of ash layers that intersected the shear bands. Strain nets were implanted on the tunnel wall to determine whether shear bands became active at the time of the eruption, 29 months earlier, or only as ice moved within a few meters of the ice wall. Results were inconclusive. The few shear bands dipped about $40^{\circ}$ toward the crater, perhaps along the slip lines shown in Figure 4.

Tunnel $\mathrm{B}$ was dug about half-way up a vertical section of the north ice wall. The rear tunnel wall was extended eastward for $8 \mathrm{~m}$, revealing a section intersected by many nearly vertical shear bands, as shown in Figure 8 . A prominent shear band intersected the ice wall at $35^{\circ}$, sub-parallel to slip lines in Figure 4. Strain nets on the tunnel walls and at the ends of holes bored $1.3 \mathrm{~m}$ into the walls were established to measure the strain-rates of inhomogeneous deformation and to determine gradients of strain-rate that might distinguish between bulk deformation and tunnel deformation. The only orderly pattern of strain was identified with vertical shear bands shearing in the same direction.

Tunnel $\mathrm{C}$ was dug near tunnel $\mathrm{B}$, but on the less-steep north-east ice wall of the crater, which angled off the nearly vertical north ice wall as shown in Figure 6. A thick ash layer in tunnel $C$ was offset slightly by two shear bands that dipped away from the crater at $45^{\circ}$ and $30^{\circ}$, respectively, and shown in Figure 8 , and shear may have been along the slip lines shown in Figure 4. As no other shear bands were found, deformation was judged to be relatively homogeneous. To test that possibility, the end of Tunnel $\mathrm{C}$ was shaped into a spherical chamber, and strain nets were mounted on the sides, end, top, and bottom next to stakes stuck at the ends of $1.3 \mathrm{~m}$ bore holes, in order to separate bulk deformation from chamber deformation. Figure 8 shows the square array of these strain nets. No clear pattern of deformation was recorded in the few days during which measurements could be made, leaving an impression of inhomogeneous deformation.

Tunnel $D$ was dug beneath a ring-fault crevasse on the upper part of the north-east ice wall, where surface melting and solifluction had produced a $45^{\circ}$ slope, as shown in Figure 8. Shear bands were almost vertical and closely spaced. A vertical shaft was dug at the tunnel end until it intersected the crevasse tip. A shear band extended vertically below the crevasse tip. Vertical shear bands in the shaft sheared through several ash layers, with lower layers being offset slightly less than upper layers and the dip of shear bands becoming slightly more vertical with depth.

Reduced shear with depth along nearly vertical shear bands was investigated by measuring the shear offset of four ash layers that intersected several shear bands exposed in a steep gully eroded down the north-east ice wall. These results are shown in Figures 9 and 10, which display shear offsets versus vertical distance up the gully, as measured from the top of a solifluction ramp about $10 \mathrm{~m}$ above the crater floor. Figure 9 shows the four ash layers and their offsets produced by intersecting shear bands. For example, 12 shear bands intersected the uppermost ash layer where it was exposed on the sides of the gully between 13.7 and $16.2 \mathrm{~m}$ above the visible base of the ice wall at the top of the solifluction ramp. The same 12 offsets, along with offsets on the other three ash layers, are plotted as points in Figure 10 and a least-squares curve is fitted to the points. Although point scatter is great, indicating inhomogeneous deformation, there is a definite tendency for shear per shear band to increase with distance up the ice wall from nearly zero at the visible base of the ice wall. The visible base was the top of the solifluction ash ramp.

\section{INTERPRETATION}

The most straightforward interpretation of the nearly vertical curving shear bands, along which shear increased from virtually zero at the base of the ice wall to a maximum at the top of the wall, is that the ice wall was bending toward the crater much like the pages of a book can be bent. Bending shear between pages increases from 


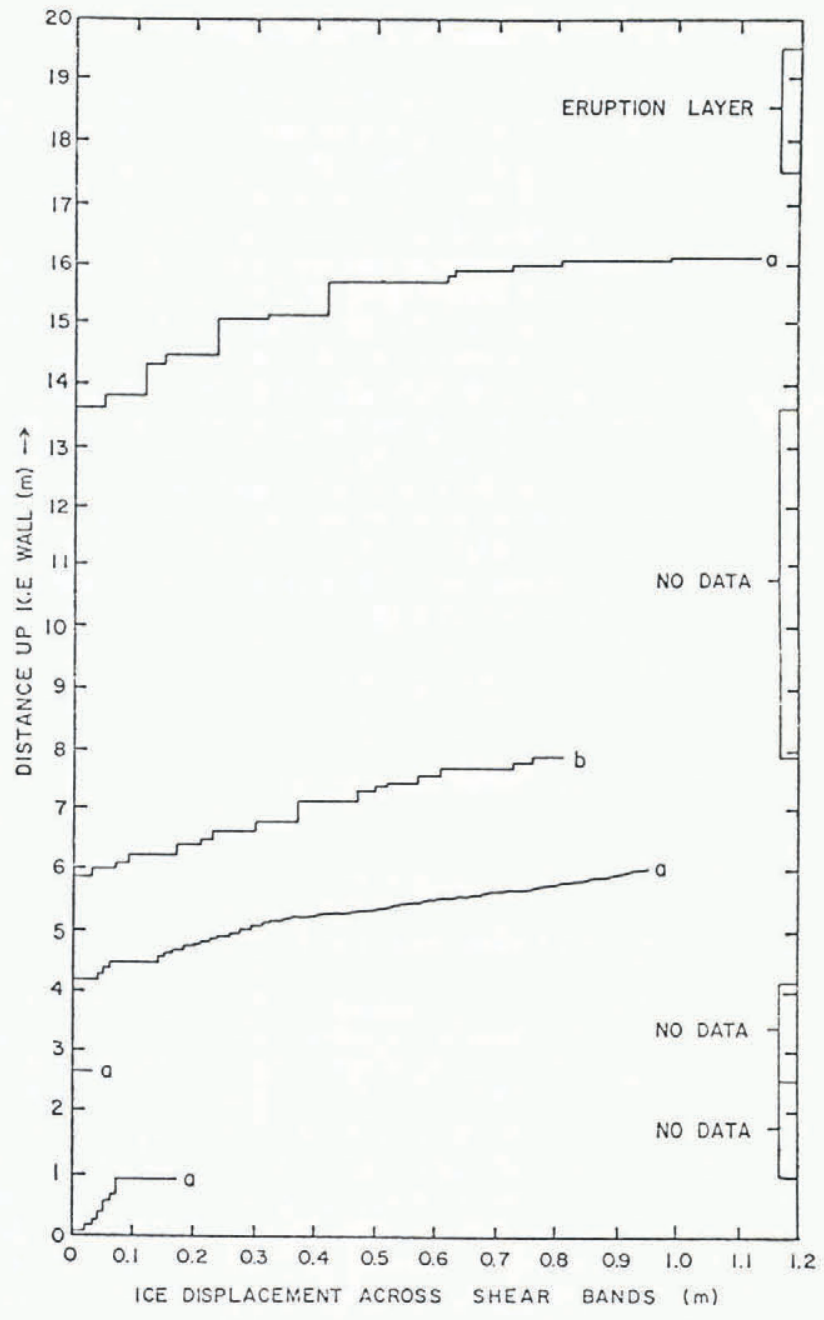

Fig. 9. Offsets across shear bands versus distance up the north-east ice wall of the crater plotted for four ash layers. These layers are three ash blankets from previous eruptions (a) and an ash-filled crevasse (b).

zero at the binding to a maximum at the unbound end. The ice wall rose above the frozen crater floor, which imposed the same rigid boundary condition as a book binding. Bending shear along shear bands was akin to bending shear between book pages. The free boundary condition at the top of the ice wall behaved like the unbound end of the book (see Fig. 11).

Horizontal displacements up a bending ice wall can be computed from the least-squares bending curve in Figure 10. Figure 11 shows how vertical shear offset $u_{z}$ along incremental length $\Delta z$ of an initially vertical shear band causes the shear band to bend through an angle $\phi$ to produce horizontal displacement $u_{x}$. From Figure 11, $\tan \phi=$ $u_{x} / \Delta z=u_{z} / u_{x}$.

$$
u_{x}=\left(u_{z} \Delta z\right)^{\frac{1}{2}} .
$$

Equation (1) is plotted in Figure 12, using of fset $u_{z}$ per $\Delta z$ summed along $z$ given by the least-squares bending curve in Figure 10.

The interpretation that nearly vertical shear bands are produced by bending shear can be tested by computing the bending curve from the bending moment and seeing whether horizontal displacements $u_{x}$ match those obtained from Equation (1). Bending moment $M(z)$ varies with vertical distance $z$ above the base of the ice wall as follows:

$$
M(z)=\left[1 / 2 \rho g w(h-z)^{2}\right][1 / 3(h-z)]=1 / 6 \rho g w(h-z)^{3}
$$

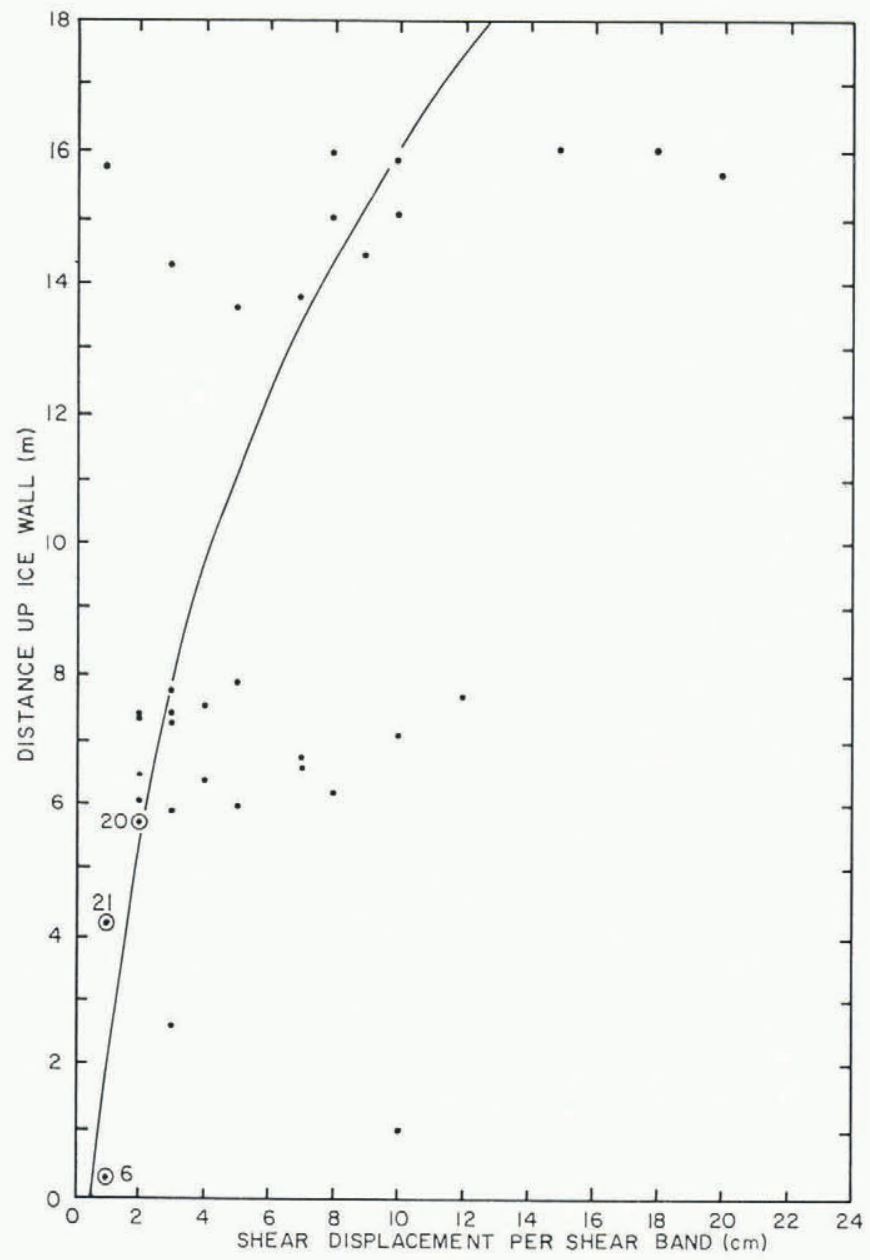

Fig. 10. Displacements per shear band versus distance up the north-east ice wall of the crater. Circled dots are for cumulative displacements of an ash layer by the number of shear bands indicated; these are in the lower ice wall where the offset across shear bands averages about $0.01 \mathrm{~m}$. The ice wall was inaccessible above $20 \mathrm{~m}$. The curve is a least-squares fit to these data.

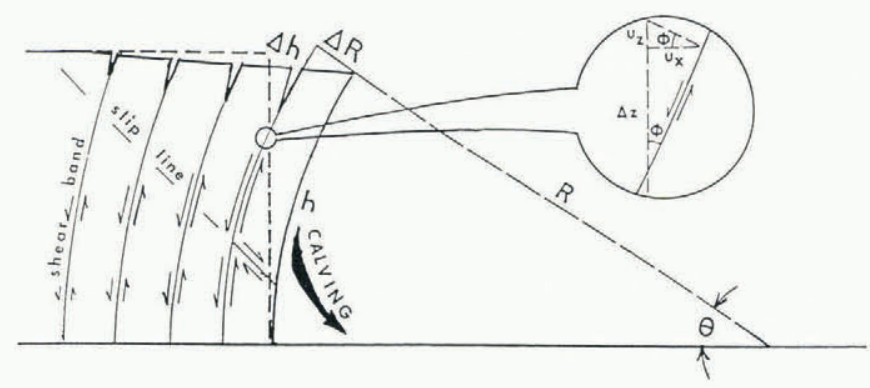

Fig. 11. Bending shear in shear bands beneath ring-fault crevasses up-slope from the calving ice wall of the Deception Island crater. Slabs calve straight down when bending shear opens crevasses to a depth where they allow the ice slab to shear along one of the slip lines in Figure 4 that intersects the ice wall at $45^{\circ}$.

are height and width of the ice wall, $\frac{1}{2} \rho g(h-z)$ is the mean hydrostatic pressure in ice at height $z$ up the ice wall that produces horizontal force $\frac{1}{2} \rho g w(h-z)^{2}$ pulling ice into the crater, and $\frac{1}{3}(h-z)$ is the lever arm from $z$ to the center of mass for this ice.

For elastic bending of the vertical ice wall, $M(z)$ causes horizontal displacements $u_{x}$ toward the crater that satisfy the flexure formula:

$$
\frac{\mathrm{d}^{2} u_{x}}{\mathrm{~d} z^{2}}=\frac{M(z)}{E I}
$$




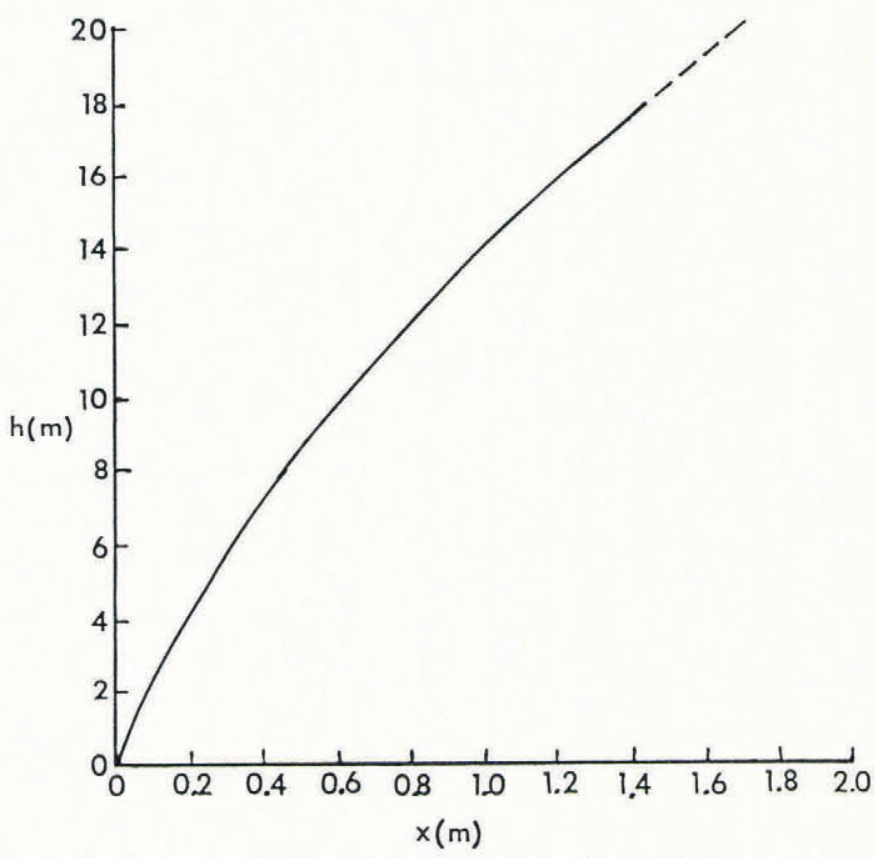

Fig. 12. The variation of horizontal bending displacement $u_{x}$ with distance $z$ up the north-east ice wall of the Deception Island crater. This curve is obtained by applying Equation (1) to the least-squares curve in Figure 10.

where $E$ is the elastic modulus and $I$ is the moment of inertia. Integrating Equation (3):

$$
u_{x}=\frac{\rho g w h^{5}}{120 E I}\left[5(z / h)+(1-z / h)^{5}-1\right] .
$$

The moment of inertia of a rectangular slab of ice over horizontal distance $x$ behind a vertical ice wall of height $h$ is:

$$
I=\int_{-x / 2}^{+x / 2} \S^{2} w \mathrm{~d} \S=\frac{w x^{3}}{12}
$$

where $\S$ is horizontal distance from the neutral axis of the slab. Combining Equations (4) and (5):

$$
u_{x}=\frac{\rho g h^{5}}{10 E x^{3}}\left[5(z / h)+(1-z / h)^{5}-1\right]
$$

If displacement $u_{x}$ occurs at velocity $v_{x}$, the creep counterpart of Equation (6) would be:

$$
v_{x}=\frac{\rho g h^{5}}{10 \eta x^{3}}\left[5(z / h)+(1-z / h)^{5}-1\right]
$$

where $n$ is the effective viscosity of ice. Creep in the shear bands should obey the flow law for ice (Glen, 1958):

$$
\dot{\varepsilon}_{x z}=\left(\sigma_{x z} / A\right)^{n}
$$

where $\dot{\varepsilon}_{x z}$ is the shear strain-rate, $\sigma_{x z}$ is the shear stress, $A$ is a hardness parameter, and $n$ is a viscoplastic exponent. The effective viscosity obtained from Equation (8) is:

$$
n=\frac{\mathrm{d} \sigma_{x z}}{\mathrm{~d} \varepsilon_{x z}^{*}}=\frac{A^{n}}{n \sigma_{x z}{ }^{n-1}} .
$$

Equation (7) can now be written:

$$
v_{x}=\frac{n \rho g h^{5} \sigma_{x z}{ }^{n-1}}{10 A^{n} x^{3}}\left[5(z / h)+(1-z / h)^{5}-1\right] .
$$

Strictly speaking, the quantity in square brackets is correct only for $n=1$.

Specifying $\sigma_{x z}$ in Equation (10) presents some difficulty when $n>1$. Is $\sigma_{x z}$ a localized shear stress in the nearly vertical shear bands and, if so, does it decrease toward the base of the ice wall in some creep relationship to the decrease in shear offsets toward the base of the ice wall? Is $\sigma_{x z}$ the shear stress between shear bands and, if so, is it homogeneous from top to bottom of the ice wall? Is the shear stress in and between shear bands the same? Easy glide in single crystals of ice can be produced by bending creep under a constant applied shear stress (Higash and others, 1964), so $\sigma_{x z}$ in the shear bands will be taken as constant and equal to basal shear stress $\tau_{0}$. Mean hydrostatic pressure at the ice wall is $\frac{1}{2} \rho g h$ and it exerts a horizontal pulling force $\left(\frac{1}{2} \rho g h\right) w h$ that is opposed by basa traction force $\tau_{0} w x$, where $x$ is the horizontal up-slope distance affected by the ice wall as a boundary condition Equating these forces and solving for $\tau_{0}$ :

$$
\tau_{0}=\rho g h^{2} / 2 x .
$$

At greater up-slope distances, $\tau_{0}$ is given by:

$$
\tau_{0}=\rho g h \alpha
$$

where $\alpha$ is the surface slope (Nye, 1951).

Up-slope distance $x$ in Equation (11) is the horizontal distance over which bending moment $M(z)$ exists. The dip of normal faults on the up-slope surface changes rather abruptly from about $80^{\circ}$ for $x<125 \mathrm{~m}$, where the nearly vertical shear bands bend toward the crater and open as ring-fault crevasses, to about $45^{\circ}$ for $x>125 \mathrm{~m}$, where slumping toward the crater occurs along ring faults, as seen in Figure 6. Taking $\rho=917 \mathrm{~kg} / \mathrm{m}^{3}, g=9.8 \mathrm{~m} / \mathrm{s}^{2}$, and $x=125 \mathrm{~m}$, Equation (11) gives $\tau_{0}=67 \mathrm{kPa}$ for an ice wall of height $h=40 \mathrm{~m}$ above the top of the solifluction ramp, where data in Figure 10 were obtained, and $\tau_{0}=109 \mathrm{kPa}$ for $h=50 \mathrm{~m}$ above the floor of the crater.

For $600 \mathrm{~m}$ further up-slope, gravity data were compatible with $h \simeq 100 \mathrm{~m}$, and the surface slope was nearly constant at $\alpha=0.06$ (Hughes and others, 1974), for which $\tau_{0}=54 \mathrm{kPa}$ in Equation (12). Laboratory creep experiments in simple shear produced shear bands like those in the ice wall within 3 months for $\sigma_{x z} \geqslant 70 \mathrm{kPa}$ at $-3^{\circ} \mathrm{C}$, the mean annual temperature on Deception Island (Hughes and Nakagawa, 1988).

Elastic bending of the ice wall produces static offsets along shear bands, offsets that decrease to zero at the base of the ice wall and that are constant in time. Viscoplastic bending of the ice wall produces dynamic offsets along shear bands that decrease to zero offset at the base of the ice wall but which increase with time. Equation (6) gives horizontal wall displacements caused by elastic bending, and Equation (10) gives horizontal wall velocities caused by viscoplastic bending, where $E=9 \times 10^{7} \mathrm{kPa}$ (Pounder, 1965), $A=19.2 \mathrm{kPa} \mathrm{a}^{1 / n}$, and $n=2.17$ (Hughes and Nakagawa, 1989). For $x=125 \mathrm{~m}$, Equation (6) gives values of $u_{x}$ that are insignificant compared to observed values plotted in Figure 12, and Equation (10) gives $v_{x}$ values for $h=40 \mathrm{~m}$ measured from the top of the solifluction ash ramp and $h=50 \mathrm{~m}$ measured from the floor of the crater at the foot of the ramp. For bending creep over up-slope horizontal distance $x=125 \mathrm{~m}$, and setting $z=h$, Equation (10) gives $v_{x}=76 \mathrm{~m} / \mathrm{a}$ for $\sigma_{x z}=57 \mathrm{kPa}$ and $v_{x}=496 \mathrm{~m} / \mathrm{a}$ for $\sigma_{x z}=109 \mathrm{kPa}$.

Equation (10) can be solved for up-slope distance $x$ over which bending creep occurs by setting $\tau_{0}=\sigma_{x z}$ and combining Equations (10) and (11):

$$
x=\left[\frac{n h^{n+3}}{5 v_{x}}\left[\frac{\rho g h}{2 A}\right]^{n}\left[5\left(\frac{z}{h}\right)+\left(1-\frac{z}{h}\right)^{5}-1\right]\right]^{\frac{1}{n+2}} \text {. }
$$

In Equation (13), bending creep produces horizontal creep velocity $v_{x}=u_{x} / t$, where horizontal displacement $u_{x}$ at height $z$ above the base of the ice wall is given by Figure 
TABLE I. HORIZONTAL DISTANCE $x$ UP-SLOPE FROM THE DECEPTION ISLAND ICE WALL

VERSUS VERTICAL DISTANCE $z$ ABOVE THE BASE OF THE ICE WALL THAT IS AFFECTED BY BENDING CREEP FOR ICE-WALL HEIGHTS OF 40 AND $50 \mathrm{~m}$

\begin{tabular}{|c|c|c|c|c|c|c|}
\hline \multicolumn{4}{|c|}{$h=40 \mathrm{~m}$} & \multicolumn{3}{|c|}{$h=50 \mathrm{~m}^{*}$} \\
\hline$z / h$ & $u_{x}$ & $v_{x}$ & $x$ & $u_{x}$ & $v_{x}$ & $x$ \\
\hline & $\mathrm{m}$ & $\mathrm{m} / \mathrm{a}$ & $\mathrm{m}$ & $\mathrm{m}$ & $\mathrm{m} / \mathrm{a}$ & $\mathrm{m}$ \\
\hline 0 & 0 & 0 & & 0 & 0 & \\
\hline 0.1 & 0.20 & 0.48 & 170 & & & \\
\hline 0.2 & 0.45 & 1.07 & 193 & 0.40 & 0.95 & 295 \\
\hline 0.3 & 0.80 & 1.90 & 199 & 0.65 & 1.55 & 309 \\
\hline 0.4 & 1.20 & 2.86 & 202 & 1.00 & 2.38 & 313 \\
\hline 0.5 & & & & 1.50 & 3.57 & 310 \\
\hline 0.6 & & & & 2.10 & 5.00 & 303 \\
\hline
\end{tabular}

*Assuming that $u_{x}=0.40 \mathrm{~m}$ in the first $10 \mathrm{~m}$ above the crater floor.

12 , and $t=0.42 \mathrm{a}$ is the $153 \mathrm{~d}$ from creation of the ice wall during the 12 August 1970 eruption to measurements of shear offsets up the ice wall shown in Figures 9 and 10 Table I shows that $x \simeq 200 \mathrm{~m}$ for $h=40 \mathrm{~m}$ and $x=300 \mathrm{~m}$ for $h=50 \mathrm{~m}$. The observed limit of bending creep is $x=125 \mathrm{~m}$, the distance when ring-fault crevasses are clearly seen to begin opening. However, it is possible that bending extends up-slope $200-300 \mathrm{~m}$ from the ice wall, but that solifluction in the thawing ash layer obscures this fact by filling the narrower ring-fault crevasses beyond $125 \mathrm{~m}$ Equation (13) predicts that bending creep extends farther up-slope from the ice wall as the wall height increases.

\section{DISCUSSION}

Calving along the ice wall occurs along ring-fault crevasses when bending creep causes the wall to overhang about $20^{\circ}$ from the vertical. Elastic bending is unimportant. Viscous bending would occur for $n=1$ in Equation (13), but laboratory creep experiments give $n=2.17$, for which Equation (13) gives an approximation of viscoplastic bending. Since the bending curve is not exact, bending that produces circular curvature can be justified almost as well and provides a simplified treatment of the calving rate.

Circular bending in which offsets along shear bands increase with increasing arc length from the base of the ice wall is illustrated in Figure 11. Bending radius $R$ causes an ice wall of height $h$ to bend through angle $\theta$, so that $\Delta h$ is the maximum shear offset across ring-fault crevasses separated by distance $\Delta R$. By similar triangles, the maximum shear strain is:

$$
\varepsilon_{x z}=\frac{1}{2}\left(\partial u_{z} / \partial x\right) \simeq \frac{1}{2}(\Delta h / \Delta R) \simeq \frac{1}{2}(h / R)=\frac{1}{2} \theta .
$$

Bending of the ice wall toward the crater is about a frozen base, so that $u_{x}=0$ at the bottom of the ice wall and surface velocity is $u_{x}=u_{\mathrm{S}}$ at the top of the ice wall. The shear strain-rate is:

$$
\dot{\varepsilon}_{x z}=\frac{1}{2}\left(\partial v_{x} / \partial z\right) \simeq \frac{1}{2}\left(u_{\mathrm{s}} / h\right)
$$

The time between calving events is:

$$
t=\frac{\varepsilon_{z x}}{\dot{\varepsilon}_{x z}}=\frac{h \theta}{u_{\mathrm{s}}} .
$$

The calving rate is:

$$
u_{\mathrm{r}}=\frac{\Delta R}{t}=\frac{u_{\mathrm{s}} \Delta R}{h \theta} .
$$

For the north-east ice wall, calving occurs for $u_{\mathrm{s}} \simeq 76 \mathrm{~m} / \mathrm{a}$, $\Delta R \simeq 4 \mathrm{~m}, h \simeq 40 \mathrm{~m}$, and $\theta=0.3 \mathrm{rad}$, which gives calving events about every 2 months and a calving rate of about $24 \mathrm{~m} / \mathrm{a}$.
Calving dynamics observed on the Deception Island ice wall can be generalized for calving ice walls standing in water of any depth short of flotation.

The major difference between calving walls grounded in water and grounded on dry land is a reduction in the horizontal pulling force as water deepens. If $h$ is height of the ice wall, $d$ is depth of the water, $\rho_{I}$ is ice density, and $\rho_{\mathrm{W}}$ is water density, the horizontal pulling force $F_{x}$ is:

$$
F_{X}=\frac{1}{2} \rho_{\mathrm{I}} g w h^{2}-\frac{1}{2} \rho_{\mathrm{W}} g w d^{2} .
$$

Equating $F_{x}$ with basal traction force $\tau_{0} w x$ gives:

$$
\tau_{0}=g\left(\rho_{\mathrm{I}} h^{2}-\rho_{\mathrm{W}} d^{2}\right) / 2 x .
$$

Equation (19) reduces to Equation (11) when $d=0$. As $d$ increases, basal shear stress $\tau_{0}$ over up-slope distance $x$ decreases and becomes zero at depth $d=h\left(\rho_{\mathrm{I}} / \rho_{\mathrm{W}}\right)$ that floats ice of thickness $h$. Reduction of $\tau_{0}$ should prevent the nearly vertical shear bands from forming, in which case the slab-calving mechanism would be suppressed.

Figure 13 shows the distribution of $F_{X}$ along $z$ for various water depths. The bending moment is simply:

$$
\begin{aligned}
M_{z} & =\int_{0}^{h-z} \frac{1}{2} \rho_{\mathrm{I}} g w(h-z)^{2} d(h-z)-\int_{0}^{d-z} \frac{1}{2} \rho_{\mathrm{W}} g w(d-z)^{2} d(d-z)= \\
& =1 / 6 \rho_{\mathrm{I}} g w(h-z)^{3}-1 / 6 \rho_{\mathrm{W}} g w(d-z)^{3} .
\end{aligned}
$$

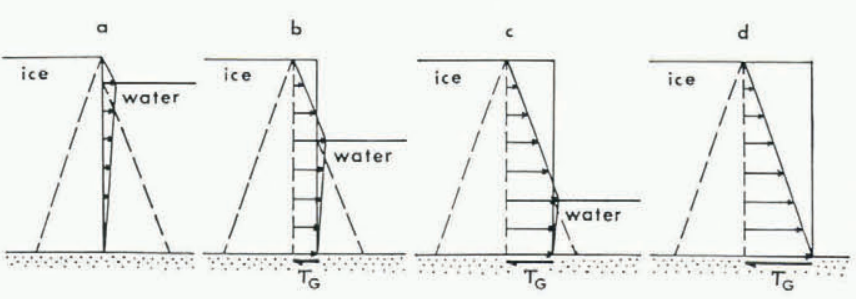

Fig. 13. The net horizontal pulling force acting on an ice wall for various water depths. Dashed lines show the linear increase of hydrostatic pressure with depth for ice and water. Basal shear stress $\tau_{0}$ exists when the ice wall is grounded.

Since $F_{x}$ increases as $h^{2}$, the pulling force is greatest at the midpoint along a calving ice wall, where wall height is usually greatest. Hence, $F_{x}$ will tend to calve arcuate bights in the ice wall. Since $F_{x}^{x}$ acts normal to the ice wall, it will become $F_{r}$, where $r$ is the radius of the bight. The calving rate $u_{r}$ subtracts from longitudinal ice velocity $u_{x}$ at the center of the bight, but increasingly less so at its sides, 


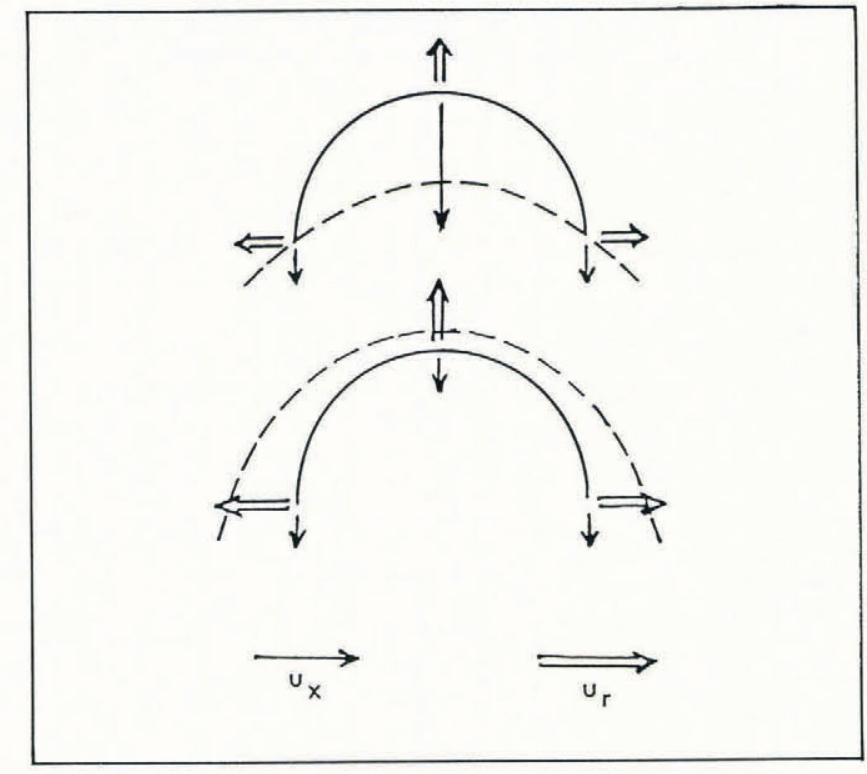

Fig. 14. The relationship between longitudinal ice velocity $u_{\mathrm{s}}$ and slab calving rate $u_{r}$ for an arcuate bight in an ice wall. The bight closes when $u_{\mathrm{s}}$ is greatest at the center (top) and widens when $u_{\mathrm{s}}$ is uniform across the bight (bottom).

where only the longitudinal component of $u_{r}$ subtracts from $u_{x}$. If $u_{x}$ is greatest in the center, the bight will tend to close, but if $u_{x}$ is uniform along the ice wall, the bight will widen (see Fig. 14). These conditions can be seen $\theta$ ver time for the calving ice wall of Columbla Glacier (Krimmel, 1987).

\section{ACKNOWLEDGEMENTS}

Other members of the Deception Island field team were H.H. Brecher, C. Parkinson, R. Curl, and M. Scholz. This work was funded by U.S. National Science Foundation grants GV-36510 and DPP-8312196. I thank K. Hutter for valuable criticisms of this work.

\section{REFERENCES}

Brecher, H., M. Nakagawa, and T. Hughes. 1974. Volcanic eruptions and the stability of glaciation on Deception Island, Antarctica. In Gonzales Ferran, O., ed.
Proceedings of the symposium on "Andean and Antarctic Volcanology Problems" (Santiago, Chile, September 1974). Rome, International Association of Volcanology and Chemistry of the Earth's Interior, 59-77.

Brown, C.S., M.F. Meier, and A. Post. 1982. The calving relation of Alaskan tidewater glaciers, with application to Columbia Glacier. U.S. Geol. Surv. Prof. Pap. $1258-\mathrm{C}$.

Fastook, J.L. and W.F. Schmidt. 1982. Finite element analysis of calving from ice fronts. Ann. Glaciol., 3, 103-106.

Glen, J.W. 1958. The flow law of ice. International Association of Scientific Hydrology Publication 47 (Symposium of Chamonix - Physics of the Motion of Ice), 171-183.

Higashi, A., S. Koinuma, and S. Mae. 1964. Bending creep of ice single crystals. Jap. J. Appl. Phys., 4(8), 575-582.

Holdsworth, G. 1969. Structural glaciology of Meserve Glacier. Antarct. J. U.S., 4(4), 126-128.

Holdsworth, G. and J.E. Glynn. 1981. A mechanism for the formation of large icebergs. J. Geophys. Res., 86(C4), 3210-3222.

Hughes, T. 1971. Nonhomogeneous strain studies on Antarctic glaciers. Antarct. J. U.S., 6(4), 89-90.

Hughes, T. 1973. Ice crater closure studies on Deception Island. Antarct. J. U.S., 8(4), 172-175.

Hughes, T. 1974. Ice crater closure studies on Deception Island. Antarct. J. U.S., 9(4), 172-174.

Hughes, T. and M. Nakagawa. 1989. Easy glide in shear bands from a calving ice wall duplicated in laboratory creep experiments. (Abstract.). Ann. Glaciol., 12, 204.

Hughes, T., C. Parkinson, and H. Brecher. 1974. Ice dynamics study of a glacial surge induced by the August 1970 eruption on Deception Island, Antarctica. In Gonzales Ferran, O., ed. Proceedings of the symposium on "Andean and Antarctic Volcanology Problems" (Santiago, Chile, September 1974). Rome, International Association of Volcanology and Chemistry of the Earth's Interior, 114-133.

Iken, A. 1977. Movement of a large ice mass before breaking off. J. Glaciol., 19(81), 595-605.

Krimmel, R.M. 1987. Columbia Glacier in 1986: 800 meter retreat. U.S. Geol. Surv. Open-File Rep. 87-207.

Lingle, C.S., T. Hughes, and R.C. Kollmeyer. 1981. Tidal flexure of Jakobshavns Glacier, West Greenland. $J$. Geophys. Res., 86(B5), 3960-3968.

Nadai, A. 1950. Theory of flow and fracture of solids. New York, McGraw-Hill.

Nye, J.F. 1951. The flow of glaciers and ice-sheets as a problem in plasticity. Proc. R. Soc. London, Ser. A, 207, 554-572.

Pounder, E.R. 1965. Physics of ice. Oxford, etc., Pergamon Press. 